\title{
Effect of Gradual Variation of Metal Composition on Stresses Generated in Weld Interfaces
}

\author{
Nandit Jadvani, Raj Shah, Vikash Singh Dhiraj* \\ Department of Mechanical Engineering, MPSTME, SVKM's Narsee Monjee Institute of \\ Management Studies (NMIMS), Shirpur Campus, Dhule, Maharashtra, India 425405 \\ * Corresponding author email: vsinghdhiraj@gmail.com
}

Received: 15 September 2016 / Revised: 22 October 2016/ Accepted: 26 October 2016 / Published: 27 October 2016

\begin{abstract}
Dissimilar metal joints formed by conventional welding creates residual stress at the interface and leads to an earlier failure than expected. The conventional methods are rapidly being replaced by advanced techniques, such as transition layer grading. This kind of transition grading aims to form the welding component akin to functionally graded material. The present paper aims to analyze different stress concentration conditions by varying temperatures, loads, and the number of transition layers. The material in the weld zone varied linearly when the number of layers was increased, which is analogous to functionally graded materials. The finite element model of a dissimilar metal welded pipe was simulated using ANSYS Workbench 14.5. Based on the executed simulations, it was observed that residual stress at the weld interface decreased as the number of layers increased up to a certain critical number of graded layers. Furthermore, negligible effect on stress reduction has been observed beyond this critical number of graded layers.
\end{abstract}

Keywords: Transition grading, Welding, Stress reduction, FEA

\section{Introduction}

Welding is a common process of joining two or more metals and the difference in the properties of joining metals plays significant role on the strength of joints. The difference in material properties such as Coefficient of Thermal Expansion (CTE), modulus of elasticity (E), Poisson's ratio combined with the joint geometry leads to stress concentration in the joint interface [1]. Also, the formation of the residual stress/strain and the induced distortions in pipe joints is another concern. In high temperature applications, each side of the joint tends to expand at a different rate due to differences in CTE, E, Poisson's ratio, as well as geometry. This results in very high stresses being developed in the dissimilar metal joints (DMJ). These high stresses can be avoided by using a suitable filler material in the welding process. The filler material is selected in such a way that the material properties lie roughly between the base metals. The difference between composition and related properties can be minimized using proper filler materials. The use of filler materials increases service life of components. But it is seen that relatively high stresses are still present at the interface [2]. These stress concentrations combined with thermal cycling and high temperatures cause creep failure in the joints after a predictably shorter time than the rest of the system. The difference in tool geometry and welding parameters induces significant changes in material flow path during welding as well as in the microstructure in the weld zone [3]. In addition, the formation of cracks in the heat affected zone (HAZ) is also a prime concern. The cracks are formed due to formation of the brittle 
Effect of Gradual Variation of Metal Composition on Stresses Generated in Weld Interfaces

intermetallic compound at the joint interface [4]. The solid solubility is essential for obtaining good quality dissimilar metal welds. The difference in melting points of the base metals is also a significant problem as one of the one base metal melts earlier than other. Often one metal melts much faster than the other one and hence they do not complete mix. This results in joints of poor quality having insufficient strength. The high thermal conductivity metals such as Copper when joined with steel dissipates the heat away from weld and causes difficulty in reaching the melting temperature [5]. The melted copper penetrates the grain boundaries of stainless steel and form cracks at HAZ. It was observed that disimilar metal weld (DMW) joints are susceptible to hydrogen embitterment in chloride solutions at room temperature [6]. It has been conclusively proved that in DMW of stainless steel and nonstainless steel, the failure load of cross tension specimen was around $75 \%$ of the lap shear specimens. Another research has concluded that the difference in grain structure may cause early failure of weld due to uneven stresses [7]. One of the major problems in metal inert gas (MIG) welding is mixing of metals in DMW [8]. Jang et al. [9] carried out tensile tests on dissimilar metal welds between low alloy steel and 316 stainless steel. They also conducted micro hardness tests to measure the variation in strength along the thickness of the weld. They reported that the strength was much greater at bottom of the weld than the top of weld. Some more researches conducted on dissimilar metal welds [10] using gas tungsten arc welding process observed that at the dissimilar metal joint interfaces cracks were developed. Some other researchers reported a similar phenomenon while working on $214 \mathrm{Cr}-1$ Mo steel and Type 316 stainless [11]. It was observed the relative effectiveness of $\mathrm{Mn}$ and $\mathrm{Ni}$ in stabilizing weld metal austenite varies with $\mathrm{Cr}$ content. They developed an empirical equation to describe the variation in the austenite stabilization. An in-depth analysis on the mechanical behaviour of a friction stir welded joint of aluminium alloy was conducted by Dilip et al [12].

The present paper contains a brief introduction of welding focusing its use in dissimilar metal joints followed by the common issues in such joints formed by conventional welding. Section 2 : Materials and Methods proposes a Weld joint of a pipe specimen by unconventional welding/joining process- Transition graded metal joint with the help of LENS (laser engineered net shaping). The finite modelling and analysis of DMJ is carried out by using an industry baseline model and is simulated for several parametric conditions to analyse the stress distribution. The results obtained are discussed for different number of layers used in grading and for varying tensile load conditions and temperature. Abrupt change in elastic properties of material, change in poison's ratio, coefficient of thermal expansion and the uneven geometry are the prime reasons of stress concentration in weld interfaces [13]. In the current paper, dissimilar metal welds in pipes made of stainless steel and carbon steel are considered. Stainless steel having higher thermal expansion rate than the carbon steel tries to expand more and hence is the main reason behind the generation of high concentration in the weld zone. The fact that at the interface the material properties- primarily the modulus of elasticity and Poisson's ratio vary abruptly further increase this stress concentration. Hence, efforts have been made by various researchers [14] [15] [16] to gradually vary the material properties in weld interface such that the variation in material properties at the weld zone is continuous rather than being abrupt. In past, various researchers have used FEA to make predictions about different welding parameters. Dhas, et al. [17] developed a FEM model to correlate the temperature and residual stresses on the weld zone. Similarly, Jayakumar et al. [18] used a 2D FE model to predict residual stress in austenitic stainless steel. A more detailed literature on friction stir welding may be found in works of Chaudhari et al. [19].

\section{Materials and Methods}

In the current research the feasibility of using transition grading technique to reduce the stress concentration in the weld zone is explored. ANSYS Workbench 14.5 has been used to simulate the DMJs in which material composition and their properties are varying along with the 
Jadvani et al., J. Mod. Mater.; Vol. 3, Issue 1, pp: 4-8, 2017

length of the weld. ANSYS Workbench is a general-purpose Finite element software [20] [21]. The solutions are dependent on the type mesh used [22] [23] [24]. Before solving any model my FEM software, it is important to perform a mesh convergence study [25] [26] [27]. A typical application of dissimilar metal welded pipes used in nuclear reactors is simulated. The CAD model as shown in Figure 1 is generated and is used to carry out the stress analysis.
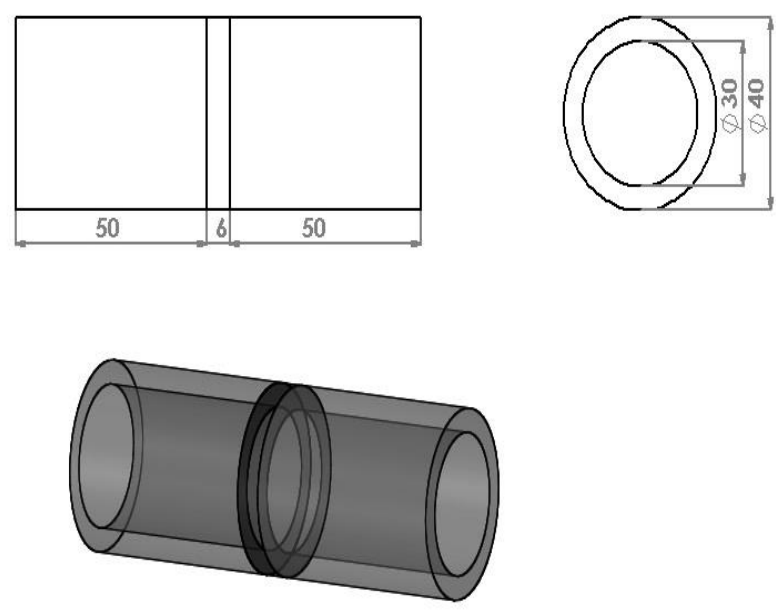

Figure 1: CAD model of the dissimilar metal welded pipe.

The model is capable of handling changes in parameters such as joint shape, size, material properties and the number of layers. The material properties considered are shown in the Table 1. The two pipes made of different materials(Material 1: Chrome moly alloy and Material 2: Stainless steel alloy) are welded by depositing layers of varying compositions which ensure gradual variation in material properties. The number of layers in the weld zone is increased in each successive simulation to study the effect on stress concentration in the interface. Three models consisting 20, 40 and 60 number of layers i.e. each weld bead thickness of $0.3 \mathrm{~mm}, 0.15 \mathrm{~mm}$ and $0.1 \mathrm{~mm}$ respectively is considered. Two loading condition are considered. In the first case, tensile pull is applied at pipe ends, and in second case compressive load is applied. The simulations are carried out at room temperature $\left(25^{\circ} \mathrm{C}\right)$ and at elevated temperature $\left(500^{\circ} \mathrm{C}\right)$ for $20 \mathrm{kN}, 35 \mathrm{kN}$ and $50 \mathrm{kN}$ loads.
Table 1: Material properties of the two base pipes.

\begin{tabular}{|c|c|c|c|c|}
\hline Materials & $\begin{array}{c}\text { \% } \\
\text { Carbon }\end{array}$ & $\begin{array}{c}\mathbf{E} \\
(\mathbf{G P a})\end{array}$ & $\mathbf{v}$ & $\begin{array}{c}\mathbf{C}_{\mathbf{T E}} \\
\left({ }^{\circ} \mathbf{C}\right)\end{array}$ \\
\hline $\begin{array}{c}\text { Material 1: } \\
\text { Chrome moly } \\
\text { alloy }\end{array}$ & 0.108 & 210 & 0.28 & $\begin{array}{c}12.9 \\
\times 10^{-6}\end{array}$ \\
\hline $\begin{array}{c}\text { Material 2: } \\
\text { Stainless steel } \\
\text { alloy }\end{array}$ & 0.08 & 193 & 0.29 & $\begin{array}{c}17.3 \\
\times 10^{-6}\end{array}$ \\
\hline
\end{tabular}

\section{Results and Discussion}

In the simulated model, material is attributed as stepwise linear. The rationale behind selecting three different numbers of layers-20, 40 and 60 is that by increasing the number of layers the material distribution in the weld zone can be assumed to be continuously linear rather than being stepwise. The width of each layer is 0.3 , 0.15 and $0.1 \mathrm{~mm}$ respectively.

Table 2: Maximum equivalent stress (in $\mathrm{MPa}$ ) at different layers under tensile loading

\begin{tabular}{|c|c|c|c|c|c|c|}
\hline $\begin{array}{c}\text { No of } \\
\text { layers }\end{array}$ & \multicolumn{2}{|c|}{20} & \multicolumn{2}{c|}{40} & \multicolumn{2}{c|}{60} \\
\hline $\begin{array}{c}\text { Load } \\
(k N)\end{array}$ & $25{ }^{\circ} \mathrm{C}$ & $\begin{array}{c}500 \\
{ }^{\circ} \mathrm{C}\end{array}$ & $25{ }^{\circ} \mathrm{C}$ & $\begin{array}{c}500 \\
{ }^{\circ} \mathrm{C}\end{array}$ & $25{ }^{\circ} \mathrm{C}$ & $\begin{array}{c}500 \\
{ }^{\circ} \mathrm{C}\end{array}$ \\
\hline $\mathbf{2 0}$ & 49.65 & 1449.7 & 42.43 & 1502.2 & 42.34 & 1489 \\
\hline $\mathbf{3 5}$ & 85.1 & 1450.6 & 74.38 & 1503.5 & 74.34 & 1490 \\
\hline $\mathbf{5 0}$ & 120.55 & 1451.6 & 106.34 & 1504.9 & 106.14 & 1491 \\
\hline
\end{tabular}

Table 2 contains the simulated maximum Von Mises stress in the weld zone at room temperature under tensile load of 20, 35 and 50 $\mathrm{kN}$. It is seen that as the number of layers increases the stress decrease. However, the reduction in stress is much more in between 20 to 40 layers as compared to 40 to 60 layers. The effect of high temperature on the stresses developed at the dissimilar metal interface is reported in Table 2. While keeping all other parameter same the environment temperature in increased to $500{ }^{\circ} \mathrm{C}$. This is done to simulate the pipes used in nuclear reactors carrying superheated steam. It is observed that at elevated temperature the increase in layers in the weld interface does not have desired effect in reducing stress. In fact, the stress in the interface increases from 20 to 40 layers and then decreases marginally from 40 to 60 layers. Interestingly it is 
Effect of Gradual Variation of Metal Composition on Stresses Generated in Weld Interfaces

observed that the increasing loads have negligible effect at elevated temperature.

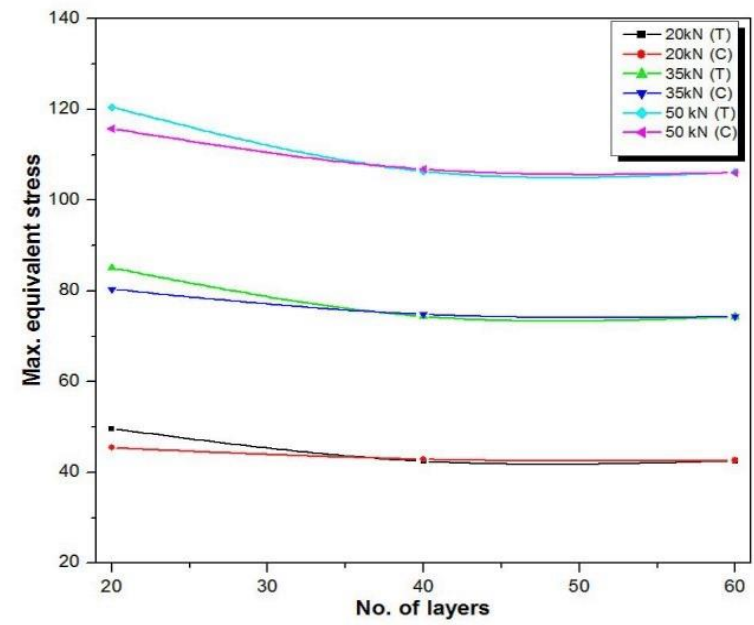

Figure 2: Max. Stress vs. number of layers at room temperature.

Figure 2 shows the variation of stresses at room temperature. It is seen that irrespective of the loading condition as the number of layers is increased, the induced stress becomes lesser.

Table 3: Maximum equivalent stress (in $\mathrm{MPa}$ ) at different layers under compressive loading

\begin{tabular}{|c|c|c|c|c|c|c|}
\hline $\begin{array}{c}\text { No of } \\
\text { layers }\end{array}$ & \multicolumn{2}{|c|}{20} & \multicolumn{2}{c|}{40} & \multicolumn{2}{c|}{60} \\
\hline $\begin{array}{c}\text { Load } \\
\text { (kN) }\end{array}$ & $25{ }^{\circ} \mathrm{C}$ & $500{ }^{\circ} \mathrm{C}$ & $25^{\circ} \mathrm{C}$ & $500{ }^{\circ} \mathrm{C}$ & $25^{\circ} \mathrm{C}$ & $500{ }^{\circ} \mathrm{C}$ \\
\hline $\mathbf{2 0}$ & 45.41 & 1447.3 & 42.882 & 1498.9 & 42.623 & 1485.8 \\
\hline 35 & 80.378 & 1446.6 & 74.828 & 1497.9 & 74.317 & 1484.7 \\
\hline $\mathbf{5 0}$ & 115.83 & 1445.8 & 106.78 & 1496.5 & 106.02 & 1483.5 \\
\hline
\end{tabular}

Table 3 shows the maximum von misses stress at $25^{\circ} \mathrm{C}$ and $500{ }^{\circ} \mathrm{C}$ under compressive loads. The nature of stress reduction observed is same as in the tensile loading condition. As expected the maximum stress in the weld zone under compressive load is lower than tensile loads. Figure 3 shows that the stress increases as layers are increased from 20 to 40 layers and then reduces after increasing the layers to 60 .

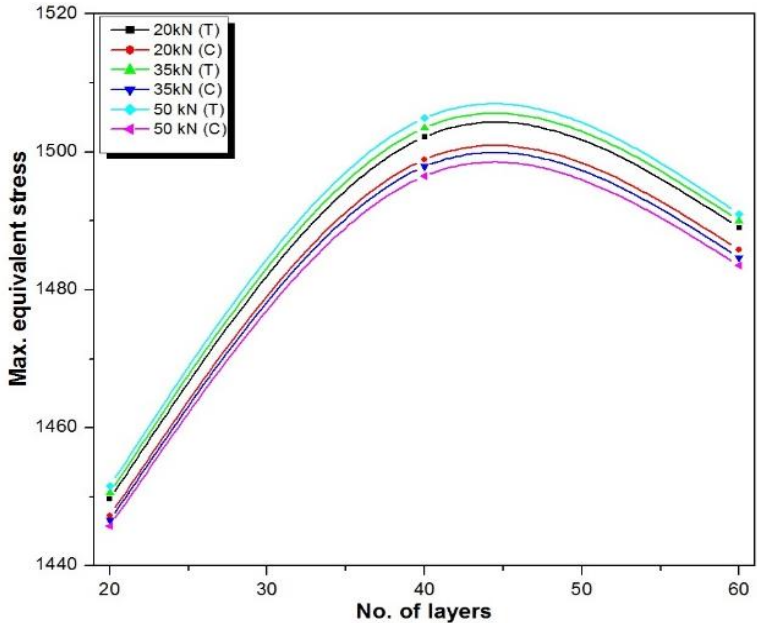

Figure 3: Max. Stress vs. number of layers at elevated temperature.

\section{Conclusions}

Stress analysis of dissimilar metal welds formed by using transition grading technique is conducted using finite element method (FEM). The developed FEM model are efficient. It is observed that about $12-15 \%$ reduction in residual stress is observed in the weld zone for dissimilar metal welded pipes under tensile load at room temperature. The reduction in residual stress is much more significant for transition from 20 to 40 as compared to 40 to 60 layers. At elevated temperature, negligible effect of transition grading scheme is seen. In general, the residual stress generated in tensile load condition are more than those under compressive loading.

\section{How to Cite this Article:}

N. Jadvani, R. Shah, and V. Dhiraj, "Effect of Gradual Variation of Metal Composition on Stresses Generated in Weld Interfaces", J. Mod. Mater., vol. 3, no. 1, pp. 4-8, Oct. 2016. doi:10.21467/jmm.3.1.4-8

\section{References}

[1] W. H. Leong, "Developing an underfill process for dense flip chip applications," in Electronics Manufacturing Technology Symposium, 1996., Nineteenth IEEE/CPMT, 1996.

[2] K. G. Watkins, M. A. McMahon and W. M. Steen, "Microstructure and corrosion properties of laser surface processed aluminium alloys: a review," Materials Science and Engineering: A, vol. 231, no. 1, pp. 55-61, 1997.

[3] D. M. Rodrigues, A. Loureiro, C. Leitao, R. M. Leal, B. M. Chaparro and P. Vila $\{\backslash \mathrm{c}\{\mathrm{c}\}\} \mathrm{a}$, "Influence of friction stir welding parameters on the microstructural and mechanical properties of AA 6016-T4 thin welds," Materials $\backslash \&$ Design, vol. 30, no. 6, pp. 1913-1921, 2009. 
[4] M. M. El-Rayes and E. A. El-Danaf, "The influence of multi-pass friction stir processing on the microstructural and mechanical properties of Aluminum Alloy 6082," Journal of Materials Processing Technology, vol. 212, no. 5, pp. 1157-1168, 2012.

[5] M. Naeem, R. Jessett and K. Withers, "Welding Of Dissimilar Materials With 1kw Fiber Laser," JK Lasers, Warwickshire, UK, 1908.

[6] M. Alenius, P. Pohjanne, M. Somervuori and H. Hanninen, "Exploring the mechanical properties of spot welded dissimilar joints for stainless and galvanized steels," WELDING JOURNAL-NEW YORK-, vol. 85, no. 12, p. 305, 2006

[7] M. Gremaud, M. Carrard and W. Kurz, "Banding phenomena in $\mathrm{Al} \square \mathrm{Fe}$ alloys subjected to laser surface treatment," Acta metallurgica et materialia, vol. 39, no. 7, pp. 1431-1443, 1991

[8] K. S. Kumar, G. Phanikumar, P. Dutta and K. Chattopadhyay, "Microstructural development of dissimilar weldments: case of MIG welding of $\mathrm{Cu}$ with $\mathrm{Fe}$ filler," Journal of materials science, vol. 37, no. 11, pp. 2345-2349, 2002

[9] C. Jang, J. Lee, J. S. Kim and T. E. Jin, "Mechanical property variation within Inconel 82/182 dissimilar metal weld between low alloy steel and 316 stainless steel," International Journal of Pressure Vessels and Piping, vol. 85, no. 9, pp. 635-646, 2008.

[10] M. D. Rowe, T. W. Nelson and J. C. Lippold, "Hydrogeninduced cracking along the fusion boundary of dissimilar metal welds," WELDING JOURNAL-NEW YORK-, vol. 78, pp. 31--s, 1999

[11] J. A. Self, D. K. Matlock and D. L. Olson, "An evaluation of austenitic Fe-Mn-Ni weld metal for dissimilar metal welding," Welding Journal, vol. 63, no. 9, pp. 282s--288s, 1984.

[12] N. D. Raja, R. Velu and S. T. Selvamani, "An Experimental Study of Mechanical Properties and Effect of Welding Speed of Friction Stir Welding on Alluminium Alloy 6061," Indian Journal of Science and Technology, vol. 8, no. 35, 2015.

[13] R. Chaudhari, A. Ingle and K. Kalita, "Stress Analysis of Dissimilar Metal Weld between Carbon Steel and Stainless Steel formed by Transition Grading Technique," Materials Today: Proceedings, vol. 2, no. 4, pp. 1657-1664, 2015.

[14] A. K. Bhaduri, S. Venkadesan, P. Rodriguez and P. G. Mukunda, "Transition metal joints for steam generators: An overview," International journal of pressure vessels and piping, vol. 58, no. 3, pp. 251-265, 1994.

[15] G. J. Brentrup, B. S. Snowden, J. N. DuPont and J. L. Grenestedt, "Design considerations of graded transition joints for welding dissimilar alloys," Welding Journal, 2012.
[16] M. Sireesha, S. K. Albert and S. Sundaresan, "Thermal cycling of transition joints between modified 9Cr--1Mo steel and alloy 800 for steam generator application," International journal of pressure vessels and piping, vol. 79 , no. 12 , pp. 819-827, 2002.

[17] L. A. K. Dhas, D. Raguraman, D. Muruganandam and B. Senthilkumar, "Temperature Prediction using Finite Element Modeling on Friction Stir Welding of AA6061AZ61," Indian Journal of Science and Technology, vol. 8 no. 31,2015 .

[18] N. Jayakumar, S. Mohanamurugan, R. Rajavel and J. A. Kumar, "Residual Stress Analysis in Austenitic Stainless Steel Weldment by Finite Element Method," Indian Journal of Science and Technology, vol. 8, no. 36, 2015.

[19] R. Chaudhari, R. Parekh and A. Ingle, "Reliability of dissimilar metal joints using fusion welding: A Review," in International Conference on Machine Learning, Electrical and Mechanical Engineering (ICMLEME:2014), 2014

[20] K. Kalita and S. Halder, "static analysis of Transversely loaded Isotropic and Orthotropic plates with centra cutout," Journal of the Institution of Engineers (India): Series C, vol. 95, no. 4, pp. 347-358, 2014.

[21] D. K. Mahanty and S. K. Maiti, "Experimental and finite element studies on mode I and mixed mode (I and II) stable crack growth I. Experimental," Engineering fracture mechanics, vol. 37, no. 6, pp. 1237-1250, 1990.

[22] K. Kalita and A. Dutta, "Free vibration Analysis of Isotropic and Composite Rectangular Plates," International Journal of Mechanical Engineering and Research, vol. 3, no. 4, pp. 301-308, 2013.

[23] K. Kalita and S. Haldar, "Natural Frequencies of Rectangular Plate With-and Without-Rotary Inertia," Journal of The Institution of Engineers (India): Series C, pp. $1-17$

[24] K. Kalita, D. Shinde and S. Haldar, "Analysis on Transverse Bending of Rectangular Plate," Materials Today: Proceedings, vol. 2, no. 4, pp. 2146-2154, 2015.

[25] A. Kumar, A. Agrawal, R. Ghadai and K. Kalita, "Analysis of Stress Concentration in Orthotropic Laminates," Procedia Technology, vol. 23, pp. 156-162, 2016.

[26] K. Kalita, R. Chaudhari and M. Ramachandran, "Mechanical Characterization and Finite Element Investigation on Properties of PLA-Jute Composite," International Journal of Computer Applications, vol. 123 no. 13,2015

[27] S. K. Maiti and D. K. Mahanty, "Experimental and finite element studies on mode I and mixed mode (I and II) stable crack growth II. finite element analysis," Engineering fracture mechanics, vol. 37, no. 6, pp. 1251-1275, 1990.

\section{Publish your research article in AIJR journals-}

$\checkmark \quad$ Online Submission and Tracking

$\checkmark$ Peer-Reviewed

$\checkmark$ Rapid decision

$\checkmark \quad$ Immediate Publication after acceptance

$\checkmark$ Articles freely available online

$\checkmark \quad$ Retain full copyright of your article.

Submit your article at journals.aijr.in
Publish your books with AIJR publisher-

Publish with ISBN and DOI.

Publish Thesis/Dissertation as Monograph.

Publish Book Monograph.

$\checkmark \quad$ Publish Edited Volume/ Book.

$\checkmark$ Publish Conference Proceedings

$\checkmark \quad$ Retain full copyright of your books.

Submit your manuscript at books.aijr.org 